\title{
Challenges in neurosurgical intraoperative consultation
}

\author{
Shalinee Rao, Aarthi Rajkumar, MD Ehtesham, Prathiba Duvuru
}

Department of Pathology, Sri Ramachandra Medical College and Research Institute, Porur, Chennai - 600 116, India

\author{
Address for correspondence: \\ Dr. D. Prathiba \\ Department of Pathology, \\ Sri Ramachandra Medical College \\ and Research Institute, Porur, \\ Chennai - 600 116, India. \\ E-mail: prathib@rediffmail.com
}

\begin{abstract}
Background: Intraoperative consultation for neurosurgical specimens can be difficult at times, despite the use of both frozen section and squash preparation. Various factors influence the diagnostic accuracy of these procedures. This study was conducted to evaluate reasons for discordant case results in neurosurgical intraoperative consultations and make a comparative analysis of these two commonly used methods to identify the possible pitfalls, errors, and limitations. Materials and Methods: All the neurosurgical cases received in the Department of Pathology for intraoperative consultation over a period of 3 years were studied retrospectively. The slides of frozen sections and squash preparation were retrieved and the diagnosis was compared with the final diagnosis given on paraffin-embedded sections. Results and Observations: A total of $6 \%$ of the cases were found to be discordant; these included angiomatous meningioma, Non-Hodgkins lymphoma, metastatic renal cell carcinoma, cerebellopontine angle fibrous meningioma, and craniopharyngioma. Highly vascular lesions, unavailability of squash preparation in a few cases and technical errors like thick smears, excessively crushed specimen, freezing, and cautery induced and crushing artifacts contributed to misdiagnosis. Conclusion: The discrepant cases need to be reviewed regularly by pathologists to familiarize themselves with the morphological changes and artifacts. The knowledge of possible errors could minimize misinterpretation and help in providing a more conclusive opinion to the operating surgeon.
\end{abstract}

Key words: Intraoperative consultation, neurosurgery, pitfalls

\section{Introduction}

Frozen section interpretation is one of the most challenging tasks in the field of pathology. Intraoperative consultation for central nervous system (CNS) lesions is frequently sought to ensure sampling of lesional tissue and to provide a preliminary diagnosis, enabling the surgeon to decide further management on the operating table. The pathologist tries to give the maximum amount of information possible to the neurosurgeon, however, there are various limiting factors. The present study was undertaken to evaluate the discordant cases in neurosurgical intraoperative consultation. A comparative analysis between frozen sections and squash preparation was done with an aim to identify the possible errors, pitfalls, and limitations with the usage of either methods.

\section{Materials and Methods}

All neurosurgical specimens that included brain and spinal lesions received in the department of pathology over the past 3 years for intraoperative consultation were studied retrospectively. The hematoxylin-eosin ( $\mathrm{H}$ and $\mathrm{E})$ stained slides of frozen section, squash preparation, and paraffin sections were retrieved. Immunohistochemistry was done wherever needed for confirmation of diagnosis. As a routine practice, both frozen and squash preparation was done on all cases. However, 8 of 120 cases studied did not have squash preparation as the tissue sent was very little. The diagnosis on frozen section and squash preparation was correlated with that of routine paraffin sections. The discordant cases were identified and possible reasons were analyzed. 


\section{Results}

Glioma constituted the predominant lesion among the total cases studied [Figure 1]. In $94 \%$ of the cases, the intraoperative diagnosis correlated with the final diagnosis while seven cases were discordant [Table 1]. Three cases were inadequate for opinion; two cases had only normal brain tissue and four specimens showed blood clot. The seven discordant cases included two cases of angiomatous meningioma [Figure 2], two cases of Non-Hodgkins lymphoma [Figure 3], and one case each of metastatic carcinoma [Figure 4], cerebellopontine angle fibrous meningioma [Figure 5], and craniopharyngioma [Figure 6]. A final diagnosis and the possible reasons for misinterpretation on the intraoperative consultation are summarized in Table 1. Various technical errors were noted on frozen sections, the predominant being the freezing artifact followed by cautery and crushing artifacts. Interpretation of squash was difficult in thick smears, excessively crushed smears, and in cases with intense vascularity.

\section{Discussion}

Intraoperative consultation of CNS lesions is considered to be an important preliminary diagnostic tool to distinguish neoplastic lesions from non neoplastic conditions at surgery. The goal of a pathologist in intraoperative setting is not to diagnose and grade every case definitively, rather to provide sufficient preliminary information to optimize the surgery..$^{[1,2]}$

The difficulty in accessing and the fragile nature of CNS tissue are the main limitation in obtaining a suitable tissue for diagnosis. ${ }^{[3]}$ The inherent soft nature of brain tissue and high water content renders poor quality frozen sections. ${ }^{[4]}$ This calls for an alternative method, such as squash preparation for a more conclusive opinion. Most errors in the interpretation of neurosurgical specimens occur when the pathologist succumbs to pressure from the operating surgeon or due to misleading clinical and radiological findings. ${ }^{[5]}$ Besides, the volume of tissue sent to the pathologist is sometimes scanty. A precise diagnosis requires a good correlation of clinical, radiological, and histopathological data. The meticulous correlation of the above details could be the reason for a high concordance rate in our study. The nature of lesions like vascularity and unconventional cell morphology may be an additional misleading factor.

Squash preparation is an effective, simple, rapid, relatively safe, and reliable technique for the diagnosis of central nervous system tumors. ${ }^{[6]}$ The knowledge of the imprint/squash preparation technique could be beneficial in centers where a facility for frozen sections

\begin{tabular}{|c|c|c|}
\hline $\begin{array}{l}\text { Intraoperative } \\
\text { diagnosis } \\
\end{array}$ & Final diagnosis & $\begin{array}{l}\text { Limitations } \\
\text { encountered }\end{array}$ \\
\hline Metastatic carcinoma & Craniopharyngioma & Freezing artifacts \\
\hline $\begin{array}{l}\text { Benign vascular } \\
\text { tumor }\end{array}$ & $\begin{array}{l}\text { Angiomatous } \\
\text { meningioma }\end{array}$ & $\begin{array}{l}\text { Freezing artifacts, Cautery } \\
\text { artifacts and vascularity }\end{array}$ \\
\hline Glioma & $\begin{array}{l}\text { Non-Hodgkins } \\
\text { lymphoma }\end{array}$ & $\begin{array}{l}\text { Freezing artifacts, Squash } \\
\text { not done }\end{array}$ \\
\hline Glioma & $\begin{array}{l}\text { Non-Hodgkins } \\
\text { lymphoma }\end{array}$ & $\begin{array}{l}\text { Freezing artifacts, Squash } \\
\text { not done }\end{array}$ \\
\hline $\begin{array}{l}\text { Angiomatous } \\
\text { meningioma }\end{array}$ & $\begin{array}{l}\text { Metastatic renal } \\
\text { cell carcinoma }\end{array}$ & $\begin{array}{l}\text { Freezing artifacts and } \\
\text { vascularity }\end{array}$ \\
\hline Schwannoma & $\begin{array}{l}\text { Fibrous } \\
\text { meningioma }\end{array}$ & $\begin{array}{l}\text { Freezing artifacts and } \\
\text { thick squash }\end{array}$ \\
\hline Glioma & $\begin{array}{l}\text { Angiomatous } \\
\text { meningioma }\end{array}$ & $\begin{array}{l}\text { Cautery artifacts and } \\
\text { vascularity }\end{array}$ \\
\hline
\end{tabular}

is unavailable, in case of a power break-down, or a lack of trained technical personnel. ${ }^{[7]}$ Squash preparation serves as a valuable diagnostic tool for certain lesions in experienced hands. The diagnostic accuracy attained with squash cytology is as high as $95.36 \% .^{[8]}$ Meningioma, lymphoma, pituitary adenoma, and choroid plexus papilloma had characteristic cytological findings in our study. The presence of cohesive sheets of cells often with meningothelial whorls or psammoma bodies and intranuclear inclusions is diagnostic of meningiomas. Lymphomas show discohesive round cells lying discretely in the absence of a fibrillary background with the presence of lymphoglandular bodies in Diff-Quick stained slides. Lymphoglandular bodies can also be visualized with Toluidine blue staining as documented by Goel, et al. in a large series of their squash study. ${ }^{[9]}$ However, this was not apparent in $\mathrm{H}$ and $\mathrm{E}$ stained squash preparation of our study. Cellular smears with round cells having a salt and pepper chromatin suggest pituitary adenoma. Three dimensional papillae with an orderly arrangement of cuboidal cells over a fibrovascular core is diagnostic of choroid plexus papilloma in an appropriate location.

Lesions which were better visualized on frozen sections included inflammatory lesions and metastatic carcinoma. Sarvargoankar, et al had a similar experience in their study where they also found frozen sections to be more beneficial in diagnosing reactive lesions. ${ }^{[4]}$ The presence of glial tissue with interspersed epithelial tumor islands suggest a metastatic carcinoma on frozen sections. The presence of intracytoplasmic mucin may assist in diagnosing adenocarcinoma, whereas intercellular bridges suggest the possibility of squamous cell carcinoma. Squash was not very helpful in diagnosing metastatic lesions as the neoplastic epithelial cells resist spreading.

Reves, et al. in a study of neurosurgical intraoperative diagnosis found frozen sections to be more accurate 


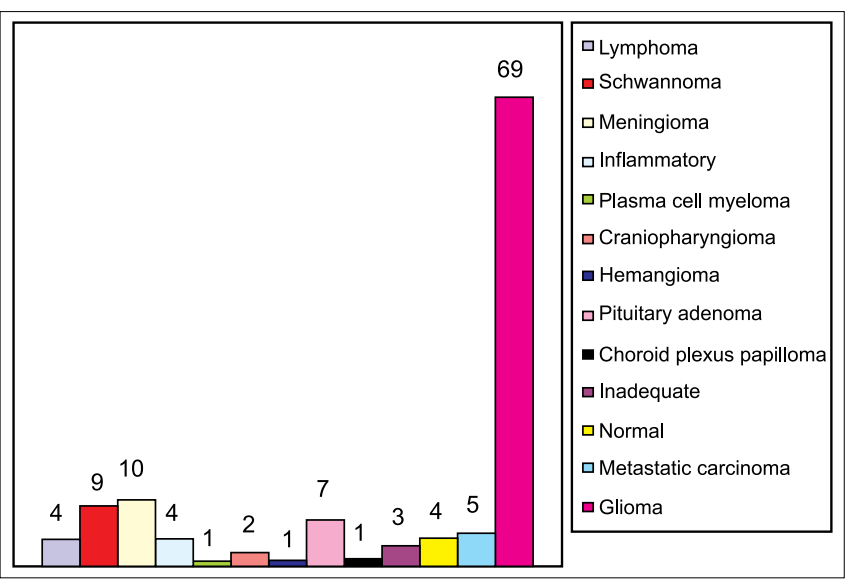

Figure 1: Final diagnosis of 120 neurosurgical cases studied

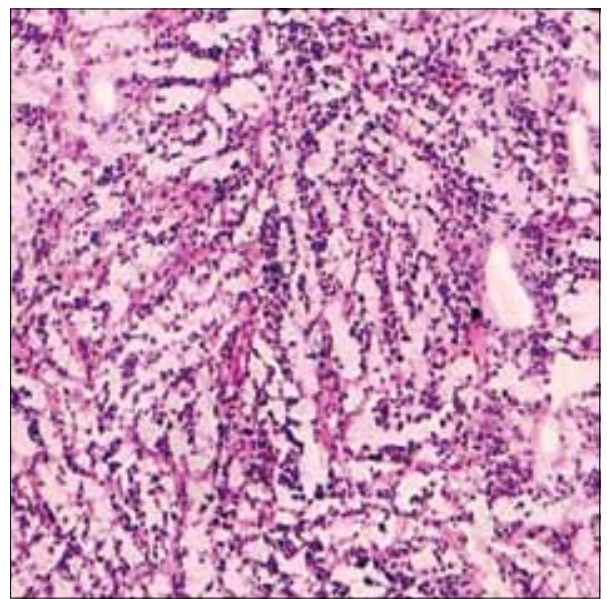

Figure 3: Non-Hodgkins lymphoma diagnosed as glioma on frozen section $(H$ and $E, \times 20)$

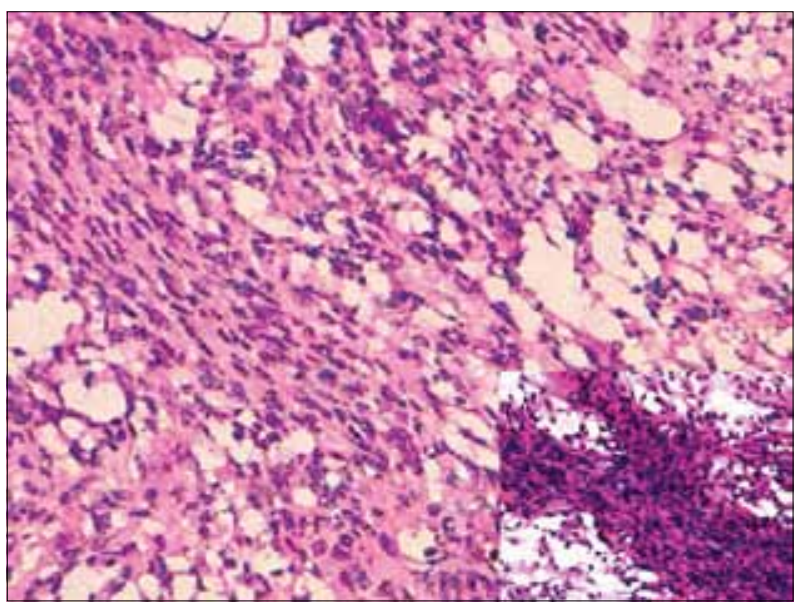

Figure 5: Fibrous meningioma misinterpreted as schwannoma $(H$ and $E$, $\times 100)$. Inset show thick squash preparation with spindle and oval cells

than imprint smears. ${ }^{[10]}$ However, cytology could be of importance in processing samples from patients of acquired immunodeficiency syndrome considering the

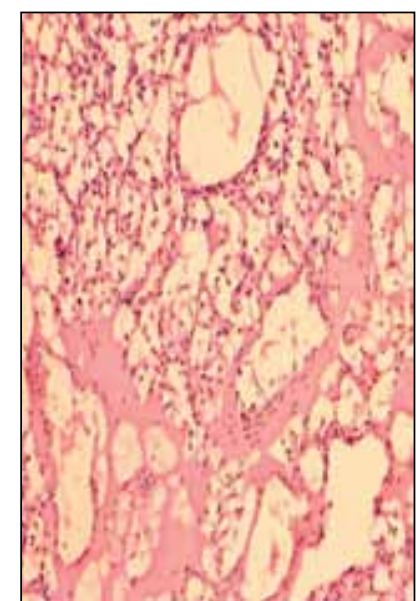

Figure 2: Angiomatous meningioma diagnosed as benign vascular tumour on frozen section $(\mathrm{H}$ and $\mathrm{E}, \times \mathbf{2 0})$

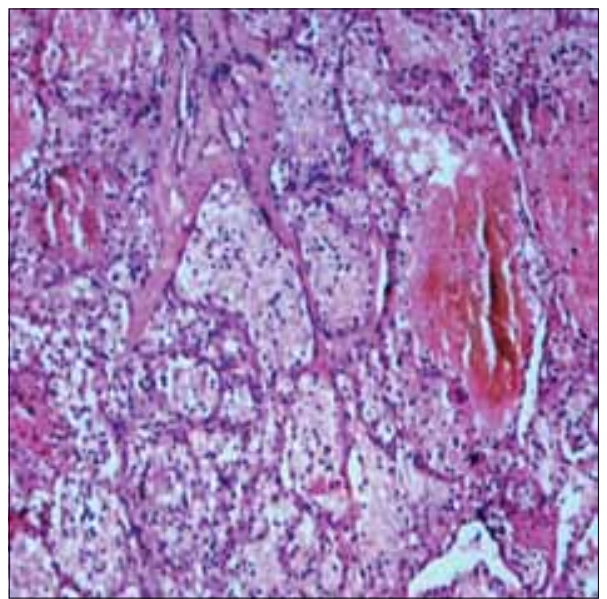

Figure 4: Metastatic renal cell carcinoma misdiagnosed as angiomatous meningioma ( $\mathrm{H}$ and $\mathrm{E}, \times \mathbf{4 0})$

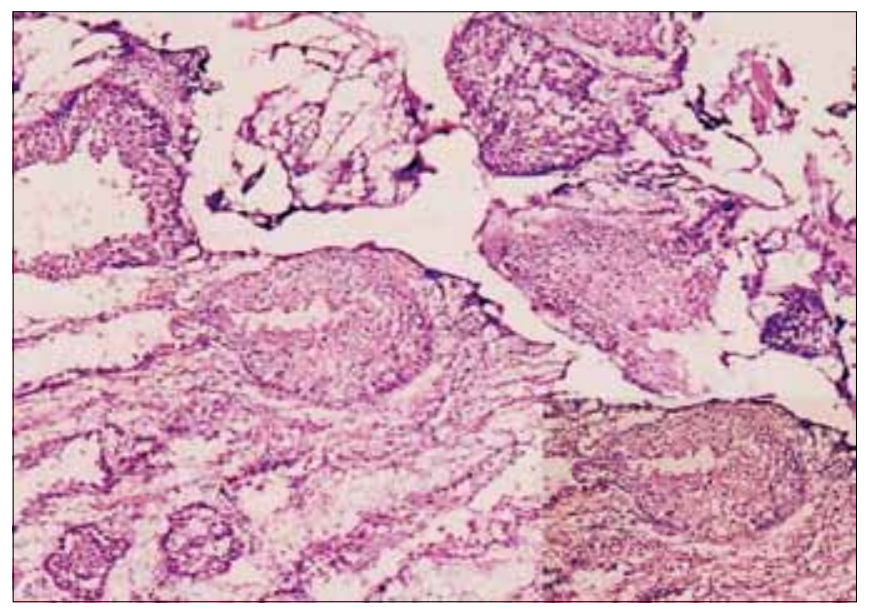

Figure 6: Craniopharyngioma reported as metastatic carcinoma ( $\mathrm{H}$ and $E, \times 40$ ), inset higher magnification of the same

contamination of instruments used by fresh unfixed tissues. ${ }^{[10]}$ This should also hold good for slow virus diseases. The combination of these two methods would 
give the best possible results as found in our study. In a similar study, Di Stefano found an accuracy of $95.29 \%$ with the combined method. ${ }^{[5]}$

An evaluation of the seven discordant cases revealed various pitfalls, which led to misdiagnosis. We defaulted in highly vascular cases that included two cases of angiomatous meningioma and 1 case of metastatic clear cell carcinoma. The misinterpretation in angiomatous meningioma resulted from emphasis given to vascularity and morphological alterations introduced by cautery artifacts. One case of craniopharyngioma was misdiagnosed as metastatic carcinoma due to the presence of pseudopapillae and solid sheets of cells with freezing artifacts. A papillary variant of craniopharyngioma could also be mistaken for choroid plexus papilloma.

Two cases of non-Hodgkins lymphoma were misdiagnosed as high-grade glioma. They were highly cellular and showed freezing artifacts. Unfortunately, these two cases did not have any squash preparation, which could have been more useful. Most specimens received for intraoperative consultation are small, which is preferably processed for frozen section; however, if there is a relatively generous specimen submitted, the pathologist may have the luxury of performing a cytologic touch imprint and/or a squash preparation technique for interpretation. ${ }^{[7]}$ It may be difficult to distinguish high-grade gliomas from lymphomas on frozen sections having artifacts. A cytological smear preparation in case of a suspected lymphoma is recommended. However, tumor cells in squash preparation spread over an abundant gliofibrillary background may simulate a glioma. ${ }^{[9]}$ In such situations, the presence of lymphoglandular bodies in squash cytology helps in lymphoma diagnosis. ${ }^{[9]}$

One case of cerebellopontine angle meningioma was misdiagnosed as schwannoma. A fibroblastic variant of meningioma can simulate schwannoma on a frozen section because of the spindle nature of cells. The decision becomes tough if the location is near the cerebellopontine angle (as noted in our study), spinal roots, cauda equina, or CNS parenchyma. In a similar study, Plesec et al, encountered difficulties involving spindle cell lesions, most commonly confusing schwannomas and meningiomas with other lesions. ${ }^{[1]}$ One case of metastatic renal cell carcinoma was misdiagnosed as angiomatous meningioma. The diagnostic error could be attributed to the fact that the pathologist gave more importance to the vascularity and foamy/clear cells, which closely resembled angiomatous meningioma. Another feature that added to the diagnostic misinterpretation was the presence of freezing artifacts, which enhanced the cytoplasmic clearing of tumor cells.
The presence of a fibrillary background in squash preparations was very helpful in diagnosing gliomas. However, the usage of both squash preparation and frozen section was found to be much more effective in diagnosing gliomas. It would be unwise to grade and subclassify gliomas on frozen sections as gliomas could be quite heterogeneous. ${ }^{[2]}$ A case of pilocytic astrocytoma, which is a Grade I tumor, may be overgraded and misdiagnosed due to vascularity and nuclear atypia. Freezing artifacts could compound the difficulties encountered. Unless the glioma shows unequivocal features of glioblastoma, the grading of malignancy should be done on a permanent section after an optimal evaluation of the entire sample. ${ }^{[1]}$

Technical errors in frozen section and squash preparation can also limit the diagnostic process. Crushing and overstretching artifacts can occur in squash preparation from applying excessive pressure along with rapid pulling apart of the smears. Smears that are too thick to evaluate result from using too much tissue or using very firm or hard tissue fragments that resist spreading. Frozen section preparation can introduce ice crystals into the tissue leading to the formation of artifactual spaces throughout the tissue, termed as freezing artifacts. Surgeons commonly use cautery during the operative procedure causing burning of tissues and this disrupts the morphology leading to difficulty in interpretation. Rarely, crushing artifacts can occur due to excessive pressure given by the surgeon on the removal of tissue; this can also alter the architecture in spite of good tissue processing. The pathologist should be aware of the above mimics and cytohistological artifacts that could be introduced during intraoperative tissue processing. Squash preparation and frozen section are procedures that complement each other and assist the pathologist in offering a useful diagnosis. It would be ideal to do both the procedures in neurosurgical intraoperative consultation. ${ }^{[4,12]}$ Diagnostic discrepancies in our study had no effect on immediate management decisions by the neurosurgeons.

\section{Conclusion}

The knowledge of artifactual changes and a regular root cause analysis of the misinterpreted cases could help in minimizing diagnostic errors.

\section{References}

1. Yachnis AT. Intraoperative consultation for nervous system lesions. Semin Diagn Pathol 2002;194:192-206.

2. Mills SE. Sternberg's diagnostic surgical pathology. $4^{\text {th }}$ ed. Philadelphia: Lippincott Williams and Wilkins; 2004.

3. Garcia JH, Budka H, McKeever PE, editors. Neuropathology: The diagnostic approach. Philadelphia: CV Mosby; 1997.

4. Savargaonkar P, Farmer PM. Utility of intra-operative consultations for the diagnosis of central nervous system lesions. Ann Clin Lab Sci 2001;31:133-9 
5. Di Stefano D, Scucchi LF, Cosentino L, Bosman C, Vecchione A. Intraoperative diagnosis of nervous system lesions. Acta Cytol 1998;42:346-56.

6. Shukla K, Parikh B, Shukla J, Trivedi P, Shah B. Accuracy of cytologic diagnosis of central nervous system tumours in crush preparation. Indian J Pathol Microbiol 2006;49:483-6.

7. Powell SZ.Intraoperative consultation, cytologic preparations and frozen section in the central nervous system. Arch Pathol Lab Med 2005;129:1635-52.

8. Iqbal M, Shah A, Wani MA, Kirmani A, Ramzan A. Cytopathology of the central nervous system, Part I: Utility of crush smear cytology in intraoperative diagnosis of central nervous system lesions. Acta Cytol 2006;50:608-16.

9. Goel D, Sundaram C, Paul TR, Uppin SG, Prayaga AK, Panigrahi MK, et al. Intraoperative cytology (squash smear) in neurosurgical practicepitfalls in diagnosis experience based on 3057 samples from a single institution. Cytopathology 2007;18:300-8.

10. Reyes MG, Homsi MF, McDonald LW, Glick RP. Imprints, smears and frozen sections of brain tumors. Neurosurgery 1991;29:575-9.

11. Plesec TP, Prayson RA. Frozen section discrepancy in the evaluation of central nervous system tumors. Arch Pathol Lab Med 2007; 131:1532-40.

12. Burger PC, Nelson JS. Stereotactic brain biopsies: Specimen preparation and evaluation. Arch Pathol Lab Med 1997;121:477-80.

Accepted on 06-02-2009

Source of Support: Nil, Conflict of Interest: None declared. 